\title{
Fracture Toughness of Composite and Unfilled Restorative Resins
}

\author{
J. C. Roberts, J. M. Powers, and R. G. Craig \\ School of Dentistry, The University of Michigan,Ann Arbor, Michigan 48109, USA
}

Fracture toughness, critical strain energy release rate, and critical stress intensity factor were determined for experimental and commercial restorative resins. A composite resin had lower resistance to crack initiation than an unfilled acrylic resin. The data were consistent zeith surface failure observed in single-pass wear studies of these resins.

\section{J Dent Res 56(7): 748-753 July, 1977.}

Wear tests on composite and unfilled restorative resins under condirions of single-pass slidin: indicate that the modes of surface failure may be characterized as ductile or brittle. ${ }^{1}$ The mode of surface failure of a material can be further evaluated by moasurement of its resistance to crack initiation and propagation. The critical stress intensity factor describes the state of stress at the ends of a crack at the onset of fracture, while the critical strain energy release rate is a measure of the cnergy necessary for crack initiation. Irwin ${ }^{2}$ derived the mathematical formulations of the critical stress intensity factor and the critical strain energy release rate from the experimental work of Griffith. ${ }^{3}$ Gumey and $M a i^{1}$ developed an experimental technique for measurement of the encrgy necessary for crack propagation or fracture toughness.

The purpose of this investigation was to measure the tracture toughness, critical stress intensity factor, and critical strain energy release rate for a commercial composite, an experimental unfilled diacrylate resin, and a coni-

Received for publication April 29, 1976.

Accepted for publication August 16, 1976.

This investigation was supported in whole by USPHS Research Grant DE-03416 from the National Institute of Dental Research, National Institutes of Health, Bethesda, Maryland 20014.

This investigation was presented at the 54th Annual Meeting of the International Association for Dental Research in Miami Beach, Florida, March 1976.

* Smile, \#1176-paste, \#31170-catalyst, Kerr Mfg. Co., Romulus, Mi.

$\dagger$ \#38-251-2-paste, \#31170-catalyst, Kerr Mfg. Co., Romulus, $\mathrm{Mi}$.

\# Sevriton, \#LAIID-powder, \#ML9MM-liquid, Amalgamated Dental Trade Distributors, Ltd., London, Eng. mercial unfilled acrylic resin. These results were correlated with data obtained from single-pass. wear studies. ${ }^{1}$

\section{Materials and Methods}

The fracture toughness ( $R$ ), the critical stress intensity factor $\left(\mathrm{K}_{\mathrm{IC}}\right)$ and the critical strain energy release rate $\left(G_{1 C}\right)$ were determined at different apparent crack velocities (V) for a commercial composite resin (A), an cxperimental unfilled diacrylate resin (B),,$\uparrow$ and a commercial unfilled acrylic resin $(\mathrm{C})$.

The resins were mixed according to the manufacturers' instructions and packed in a rectangular hole $(20 \mathrm{~mm}$ long, $4 \mathrm{~mm}$ wide, and $2.5 \mathrm{~mm}$ deep) in a four-piece rectangular die

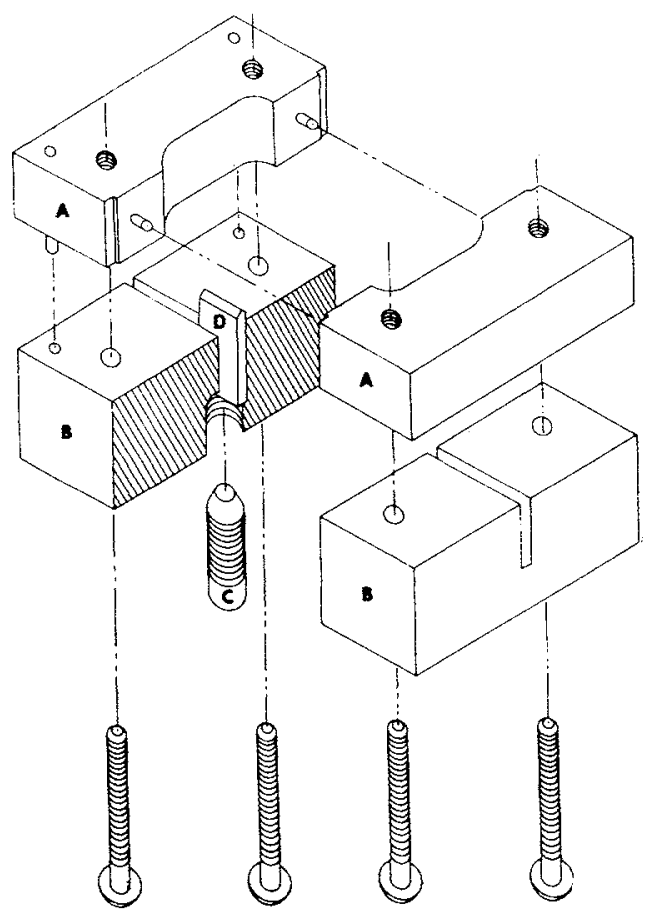

FIG 1.- Orthographic drawing of fracture toughness die. 


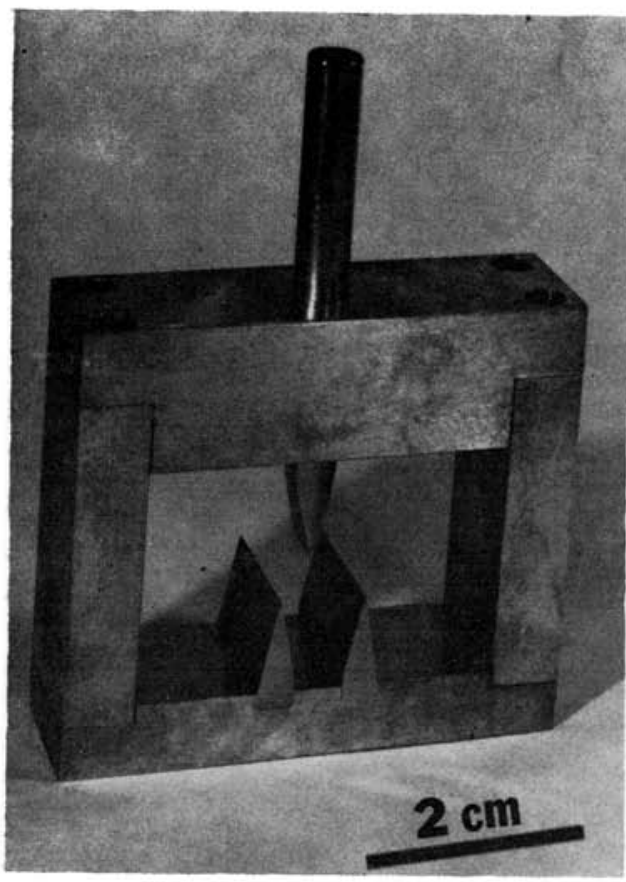

FIG 2.-Three-point bending fixture.

( $38 \mathrm{~mm}$ long, $19 \mathrm{~mm}$ wide, and $14 \mathrm{~mm}$ high). Prenotching of the specimens was accomplished by means of a spacer inserted in the die (Fig. 1). The samples were allowed to polymerize at $37 \mathrm{C}$ for 24 hours before testing.

The specimens were loaded in three-point bending by a test fixture placed on a compression load cell on a testing machine. $\S$ The threepoint bending fixture consisted of iwo stainless steel knife edges $(0.246 \mathrm{~mm}$ tip radius) that supported the specimen while being loaded from above by a cylindrical tapered rod $(0.246$ $\mathrm{mm}$ tip radius) (Fig 2). Loads were applied at crosshead rates of $0.05,0.10$, and $0.50 \mathrm{~cm}$ ' minute. The load and deflection data were taken from the chart recorder.

load-deflection data were obtained for use in calculation of fracture toughness $(\mathrm{R})$ by the formula,${ }^{5} \mathrm{R}=(\mathrm{P} \delta / 2) /(\mathrm{Bw}-\mathrm{aB})$, where $\mathrm{P}$ is load at failure, $\delta$ is deflection at failure, $\mathrm{B}$ is specimen width, $w$ is specimen height, and a is notch length. The critical stress intensity factor $\left(\mathrm{K}_{\mathrm{IC}}\right)$ was calculated by the formula, ${ }^{6}$ $\left.\left.\mathrm{K}_{\mathrm{IC}}=\{3 \mathrm{PL} \sqrt{\mathrm{a}}) / 2 \mathrm{Bw}^{2}\right)\right\}\{1.93-3.07(\mathrm{a} / \mathrm{w})$ $+14.53(\mathrm{a} / \mathrm{w})^{2}-25.11\left(\mathrm{a} / \mathrm{w} /{ }^{3}+25.80(\mathrm{a} / \mathrm{w})^{4}\right\}$, where $\mathrm{P}$ is load at failure, $\mathrm{L}$ is length between

\$ Model TT-BM, Instron Corporation, Canton, Ma.

* JSM-U3, Japan Electron Optics Laboratory, Akishima, Jap. knife edges, a is notch length, w is specimen height, and $\mathrm{B}$ is specimen width. The critical strain energy release rate $\left(\mathrm{G}_{\mathrm{IC}}\right)$ was calculated by the formula, ${ }^{7} \mathrm{G}_{\mathrm{IC}}=\mathrm{K}_{\mathrm{ic}}{ }^{2} / \mathrm{E}$, where $\mathrm{E}$ is the modulus of elasticity. The apparent crack velocity (V) was calculated by the formula, ${ }^{5}$ $\mathrm{V}=\left(1 / \sqrt{2} \pi \mathrm{t}_{\mathrm{f}}\right)\left(\mathrm{K}_{\mathrm{IC}}{ }^{2} / \sigma_{y}\right)$, where $\mathrm{t}_{\mathrm{f}}$ is time of the event and $\sigma_{y}$ is yield strength. The modulus of elasticity and $0.1 \%$ yield strength of materials $\mathrm{A}$ and $\mathrm{C}$ were determined experimentally from three-point bending of unnotched specimens.

Twenty samples of material $\mathrm{A}$ and five samples each of materials B and $\mathrm{C}$ were tested at each crosshead rate. A linear regression model $^{8}$ was used to analyze the data. A scanning electron microscope* was used to study the fracture surfaces.

\section{Results}

The fracture toughness ( $R$ ) increased with increasing apparent crack velocity (V) (Fig 3 ). The fracture toughness of the commercial composite (A) was lower than that of the unfilled diacrylate resin (B) or the commercial unfilled acrylic resin (C). A least squares regression on the fracture toughness versus apparent crack velocity data showed that at the $95 \%$ level of confidence, 64,11 , and $13 \%$ of the data could be explained by the regression for materials $\mathrm{A}, \mathrm{B}$, and $\mathrm{C}$, respectively.

The critical strain energy release rate $\left(\mathrm{G}_{\mathrm{IC}}\right)$ increased with increasing apparent crack velocity (V) (Fig 4). The critical strain energy release rate was lowest for material $\mathrm{A}$, the commercial composite, and highest for material C, the commercial unfilled acrylic resin. The critical strain energy release rate was not calculated for material B, because the modulus of elasticity was not measured. The least squares regression on the critical strain energy release rate versus apparent crack velocity data showed that at the $95 \%$ level of confidence, 63 and $99 \%$ of the data could be explained by the regression for materials $\mathrm{A}$ and $\mathrm{C}$, respectively; however, this correlation may be misleading because both $\mathrm{G}_{\mathrm{IC}}$ and $\mathrm{V}$ were calculated from $\mathrm{K}_{\mathrm{IC}}$.

The critical stress intensity factor $\left(\mathrm{K}_{\mathrm{IC}}\right)$ also increased with increasing apparent crack velocity (V) (Fig 5). The critical stress intensity factor, which is a measure of the intensity of stress around a crack, was higher for materials $\mathrm{A}$ and $\mathrm{C}$ than for material $\mathrm{B}$.

Scanning electron photomicrographs of the fracture surfaces of materials $\mathrm{A}, \mathrm{B}$, and $\mathrm{C}$ at a crosshead rate of $0.1 \mathrm{~cm} /$ minute are shown in 
Fig 3.-Fracture toughness (R) versus apparent crack velocity (V) for materials $A, B$, and $\mathrm{C}$.
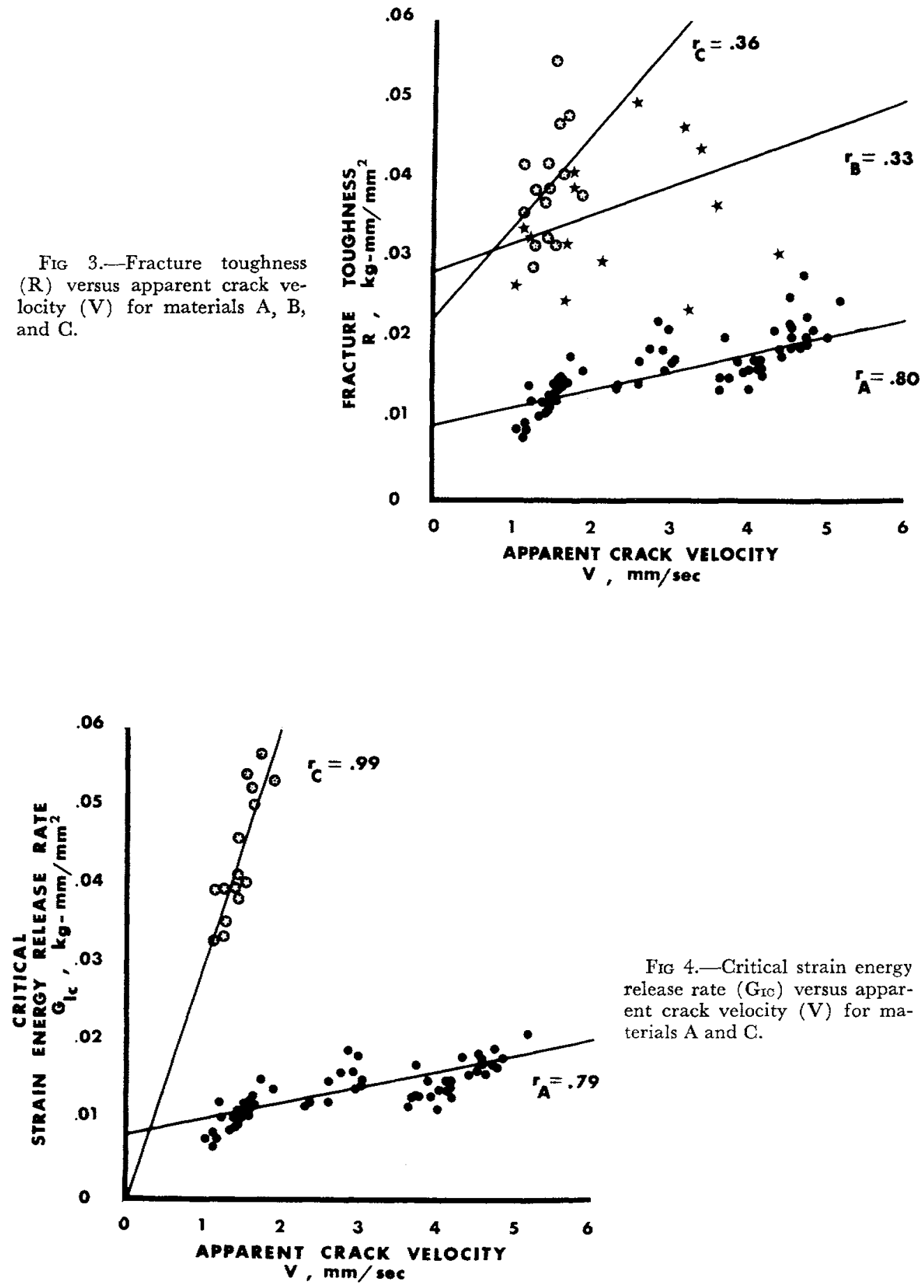

FIG 4.-Critical strain energy release rate $\left(\mathrm{G}_{\mathrm{TC}}\right)$ versus apparent crack velocity (V) for materials $\mathrm{A}$ and $\mathrm{C}$. 
FIG 5.-Critical stress intensity factor $\left(\mathrm{K}_{\mathrm{IC}}\right)$ versus apparent crack velocity (V) for materials $\mathrm{A}, \mathrm{B}$, and $\mathrm{C}$.
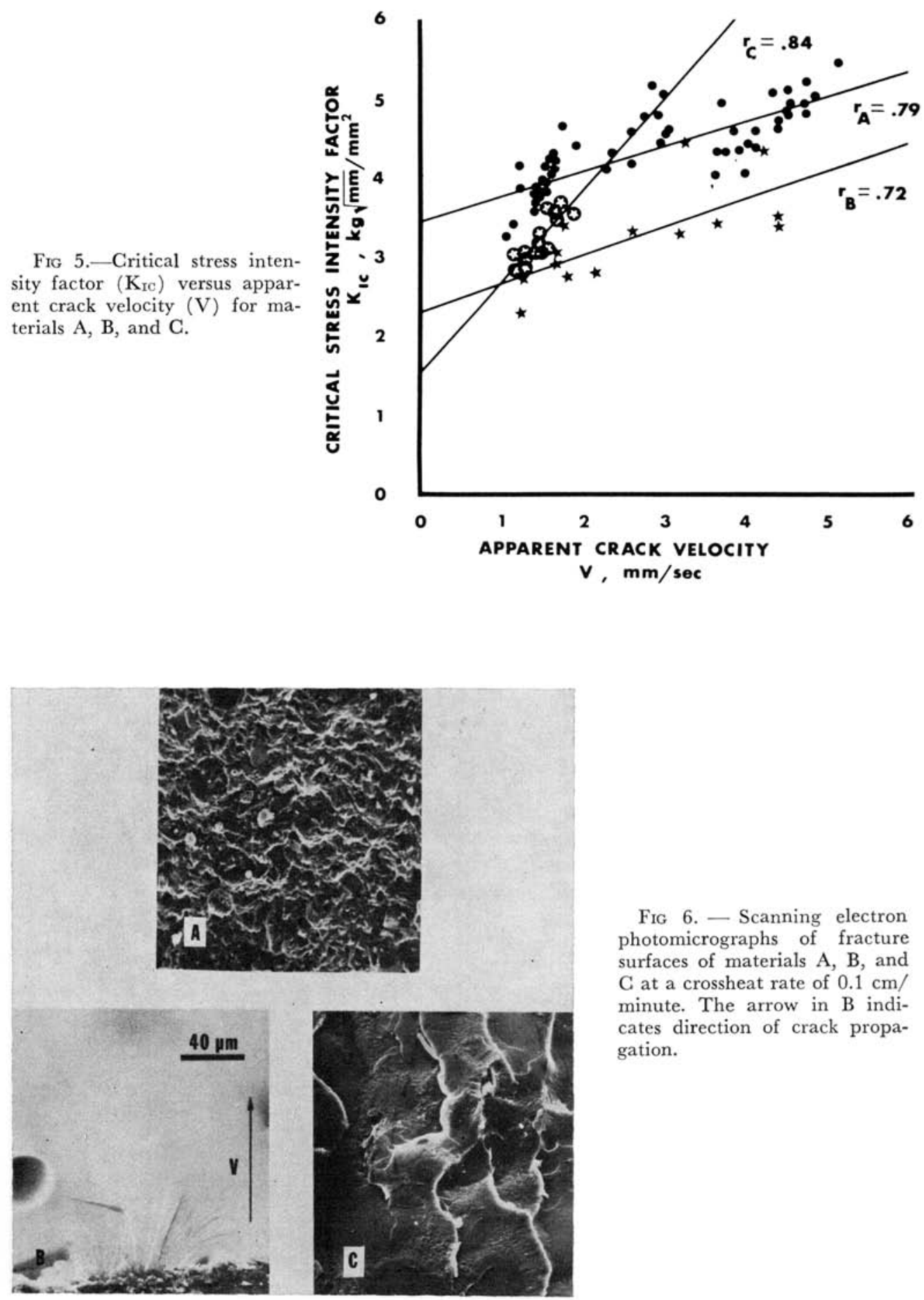

FIG 6. - Scanning electron photomicrographs of fracture surfaces of materials A, B, and $\mathrm{C}$ at a crossheat rate of $0.1 \mathrm{~cm} /$ minute. The arrow in $\mathrm{B}$ indicates direction of crack propagation. 
Fig 6. The fracture surfaces of materials B and $\mathrm{C}$ had fracture markings which indicated the direction of crack propagation (see arrow).

\section{Discussion}

The testing of materials $\mathrm{A}, \mathrm{B}$, and $\mathrm{C}$ under conditions of three-point bending resulted in the formation of unstable crack growth. The growth of an unstable crack cannot be arrested and beyond the energy required to initiate the crack, no additional energy is required to propagate it. Thus, the fracture toughness becomes a measure of the energy required to initiate a crack and should be the same as the critical strain encrgy release rate.

There was high correlation between the values of critical strain energy release rate $\left(\mathrm{G}_{\mathrm{IC}}\right)$ and fracture toughness (R). At an apparent crack velocity of $4 \mathrm{~mm} / \mathrm{sec}$, for example, the ranges of $G_{I C}$ and $R$ for material $A$ were $.013-.018 \mathrm{~kg} \cdot \mathrm{mm} / \mathrm{mm}^{2}$ and $.014-.017 \mathrm{~kg} \cdot \mathrm{mm} /$ $\mathrm{mm}^{2}$, respectively. The ranges of $\mathrm{G}_{\mathrm{IC}}$ and $\mathrm{R}$ for material $\mathrm{C}$ at an apparent crack velocity of 1.5 $\mathrm{mm} / \mathrm{sec}$ were $.038-.046 \mathrm{~kg} \cdot \mathrm{mm} / \mathrm{mm}^{2}$ and .029 $.055 \mathrm{~kg} \cdot \mathrm{mm} / \mathrm{mm}^{2}$, respectively.

The commercial composite (A) had a lower fracture toughness and critical strain energy release rate than the experimental unfilled diacrylate resin (B) or the commercial unfilled acrylic resin (C). Evidently addition of silane-treated, inorganic particles to the diacrylate matrix results in a harder, but less tough material that is more prone to cracking.

The relatively large scatter of fracture toughness data for materials $\mathrm{B}$ and $\mathrm{C}$ was due primarily to air bubbles entrapped in the materials during mixing and polymerization. Precautions were taken during mixing to ensure a void-free sample; however, the highly viscous nature of the liquid-liquid system of material $\mathrm{B}$, the experimental unfilled diacrylate resin, and the fast setting time of material $\mathrm{C}$, the commercial unfilled acrylic resin, resulted in entrapped air bubbles in the fully polymerized specimens. A larger sample size should be used to increase the precision of the measurement of fracture toughness and critical strain energy release rate.

The critical stress intensity factor $\left(\mathrm{K}_{\mathrm{IC}}\right)$ describes the state of stress at the ends of a crack during crack initiation. The two commercial materials with particles [commercial unfilled acrylic resin (C) contains poly (methyl methacrylate) beads and the commercial composite (A) contains inorganic filler particles] were less notch-sensitive than the experimental unfilled diacrylate resin (B).

The fracture surface of material A was rough because of pull-out of the filler particles and gave no indication as to the direction of crack propagation. Material $\mathrm{C}$ is a two-phase acrylic which consists of poly (methyl methacrylate) beads in a poly (methyl methacrylate) matrix. Parabolic fracture markings, which indicate the direction of crack propagation, were also observed by Kusey and Turner ${ }^{9}$ and Causton $^{10}$ in dental acrylic resins. Material B, the experimental unfilled diacrylate resin, had a glassy appearance with fracture markings characteristic of a brittle material.

The wear of restorative resins in a singlepass sliding is determined by the resistance to penetration as well as mode of surface deforma-
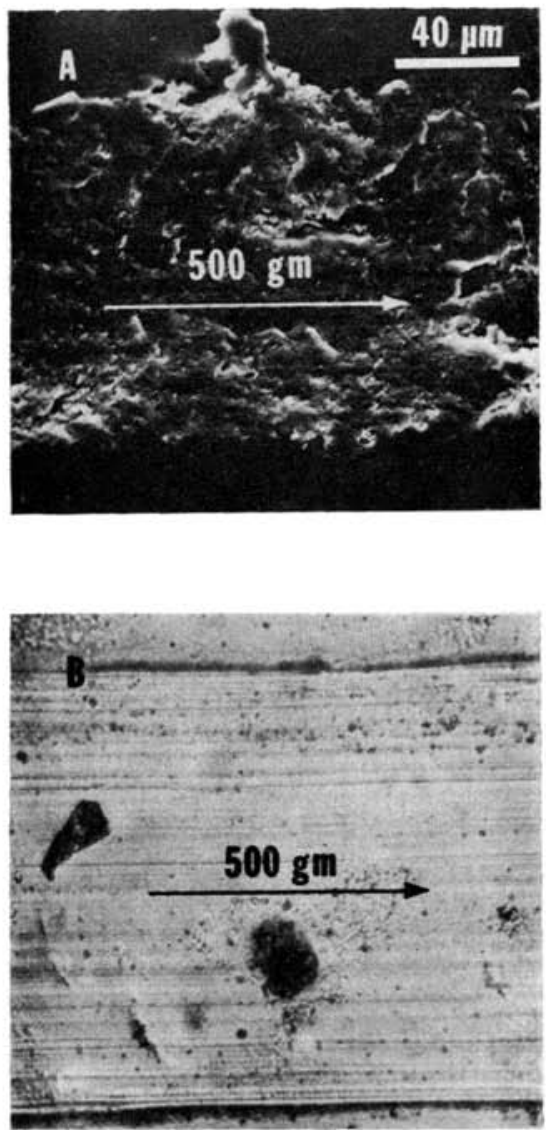

Fig 7.--Scanning electron photomicrographs of single-pass wear scars. ${ }^{1} \mathrm{~A}$, material A under $500 \mathrm{gm}$ normal load. B, material C under $500 \mathrm{gm}$ normal load. 
tion. ${ }^{1}$ Material A, the commercial composite, had a brittle mode of surface failure (see Fig $7, \mathrm{~A})$ and an average resistance to crack initiation of $0.015 \mathrm{~kg} \cdot \mathrm{mm} / \mathrm{mm}^{2}$. Material $\mathrm{C}$, the commercial unfilled acrylic resin, had a ductile mode of surface failure (see Fig 7, B) and an average resistance to crack initiation of 0.042 $\mathrm{kg} \cdot \mathrm{mm} / \mathrm{mm}^{2}$. Therefore, a relationship appears to exist between the modes of surface failure in singli:-pass wear studies ${ }^{1}$ and the resistance to crack initiation in testing of fracture toughness.

\section{Conclusions}

The fracture toughness and critical strain energy release rate, which measure the resistance to crack initiation, were determined for a composite resin, an experimental unfilled diacrylate resin, and an unfilled acrylic resin in three-point bending. The commercial composite had the lowest resistance to crack initiation, while the commercial unfilled acrylic resin had the highest resistance to crack initiation. The critical stress intensity factor, which is a measure of the stress level around a crack, was highest for the commercial composite. The fracture toughness data were consistent with the modes of surface deformation observed in single-pass wear studies of restorative resins.

\section{References}

1. Powers, J.M.; Roberts, J.C.; and Craig, R.G.: Surface Failure of Commercial and Experimental Restorative Resins, J Dent Res, 55:432-436, 1976.

2. IRwin, G.R.: Analysis of Stresses and Strains Near the End of Crack Traversing a Plate, Int Appl Mech 24:361--371, 1957.

3. Griffith, A.A.: The Phenomena of Rupture and Flow of Solids, Phil Trans Roy Soc, London A221:163-198, 1920.

4. Gurney, C. and MaI, Y.W.: Stability of Cracking, Engineering Fracture Mechanics 4:853-863, 1972.

5. Atrins, A.T.: Personal communication, October, 1974.

6. Brown, W.F. JR., and Srowley, J.E.: Plane Strain Crack Toughness Testing of High Strength Metallic Materials, ASTM STP No. 40, Philadelphia, Pa., American Society for Testing and Materials, 1973, $129 \mathrm{pp}$.

7. KNotT, J.F.: Fundamentals of Fracture Mechanics, New York, John Wiley \& Sons, $1973,273 \mathrm{pp}$.

8. University of Michigan, Statistical Research Laboratory: A Manual of Elementary Statistics Using $M I D A S$, Ann Arbor, Statistical Research Laboratory, 1975, $301 \mathrm{pp}$.

9. Kusey, R.P., and Turner, D.T.: Fractography of Poly (methyl methacrylates), J Bio med Mater Res Symposium 6:89-98, 1975.

10. Gauston, B.E.: Fracture Mechanics of Dental Poly (methyl methacrylate), I Dent Res 54:339-343, 1975. 